
\title{
R Research S Surare of \\ Technical Efficiency of Teff Farms Controlling for Neighborhood effects in Ethiopia
}

Asmiro Abeje Fikadu ( $\square$ asmiro2013@gmail.com )

Aksum University

Thomas Heckelei

institute for Food and Resource Economics, Bonn University

Tesfaye Berhanu Woldeyohanes

Institute for Food and Resource Economics, Bonn University

\section{Research}

Keywords: CRE estimation, Ethiopia, Neighborhood effect, SLX model, Technical efficiency, Teff, Translog production function

Posted Date: May 28th, 2020

DOl: https://doi.org/10.21203/rs.3.rs-30863/v1

License: (c) (1) This work is licensed under a Creative Commons Attribution 4.0 International License. Read Full License 


\title{
Technical Efficiency of Teff Farms Controlling for Neighborhood effects in Ethiopia
}

\author{
Asmiro Abeje Fikadu ${ }^{\mathrm{a} *}$, Thomas Heckelei ${ }^{\mathrm{b}}$, Tesfaye Woldeyohanes ${ }^{\mathrm{b}}$ \\ ${ }^{a}$ Department of Agricultural Economics, Aksum University, 314 Shire, Ethiopia \\ ${ }^{b}$ Institute for Food and Resource Economics, Bonn University, Nußallee 21, 53115, Bonn, Germany \\ E-mail address: thomas.heckelei@ilr.uni-bonn.de and tesfaye.woldeyohanes@ilr.uni-bonn.de
}

*Corresponding author: Department of Agricultural Economics, Aksum University, Shire, Ethiopia

E-mail address: asmiro2013@gmail.com

\begin{abstract}
Teff can be called the lifeblood of the majority of Ethiopians. However, Teff production is constrained by farmers' own and neighbor farmers' socioeconomic, demographic, intuitional, and farm characteristics that decrease Teff productivity. To fill this gap, a combination of modern technologies with a better level of farm efficiency becomes indispensable. Hence, this study aims to examine the technical efficiency of Teff farms controlling for neighborhood effects in Ethiopia using 858 Teff farmers. The stochastic frontier translog production and Spatial Lagged Explanatory (SLX) models are estimated using two waves of panel data from the Ethiopian socioeconomic survey. The unobserved heterogeneity has been controlled for by a correlated random effect estimation. The results show that the average technical efficiency of Teff farm is $78.5 \%$, indicating that farmers have about $21.5 \%$ likelihood for improving their Teff farm efficiency, averagely. Besides, the estimated correlated random effect of the spatial lagged explanatory model indicates that gender, age, education, family size, community participation, planting method, average neighbors' community participation, average neighbors' planting method, average neighbors' mineral fertilizer application, and average neighbors' use of improved seed were found to significantly affect the level of technical efficiency of Teff farms in the study area. Moreover, we show that controlling for the neighborhood effects in the estimation of technical efficiency of Teff production statistically and significantly changes the inferences. Therefore, neighborhood effects can be the best alternative platform for farm knowledge transmission and use as a development actor if properly managed and organized.
\end{abstract}

Keywords: CRE estimation, Ethiopia, Neighborhood effect, SLX model, Technical efficiency, Teff, Translog production function 


\section{Introduction}

In Ethiopia, the agricultural sector is the cornerstone of the Ethiopian economy which contributes about 35.8\% and 70\% for GDP and employment, respectively, in 2017 (CIA, 2017; World Bank, 2017). For long, agriculture has been considered as a growth catalyst for other sectors of the economy. Despite its main contribution to the Ethiopian economy, agricultural productivity remained low due to small-scale subsistence farming (Spielman et al., 2010), inefficient way of the production system (Bachewe et al., 2018) and other biotic and abiotic factors (Aung, 2012). The enhancement of the total production, productivity, and self-sufficiency (food security) are priority objectives for the Ethiopian government.

Cereal crops account for $60 \%$ of rural employment Quintin and Tefera (2013), 80\% of the total cultivated land and $87.5 \%$ of grain crops production in Ethiopia (CSA, 2018a). Teff is one of the targeted cereal crops by the Ethiopian government to increase its production, productivity, and efficiency. It is the main staple cereal crop, which is widely cultivated throughout the country and used to prepare traditional Ethiopian food (injera ${ }^{1}$ ). Most of the Ethiopian people rely on Teff for their food consumption (Crymes, 2015). Hence, Teff can be considered as the lifeblood of the majority of Ethiopia. About 6.77 million farmers produced Teff (CSA, 2018a) and it accounts for $23.85 \%$ of the total cereal crop's cultivated area (CSA, 2018a); this indicates that Teff is the dominant crop among cereal crops in terms of land allocation. Figure(1) shows that the productivity of Teff estimated at 0.835 ton/ha and 1.75 ton/ha in 1996 and 2018, respectively; indicating that yield has increased over time though slowly (CSA, 1996-2018). On the other hand, part of Teff production increment has been existed due to the expansion of cultivated farmland; might not through improved farm technologies (Bachewe et al., 2018) and (Taffesse et al., 2012).

As depicted in figure(2), the average minimum and maximum estimated Teff yield at the research station for different improved Teff varieties is 1.94ton ha $\mathrm{ha}^{-1}$ and 2.69ton $\mathrm{ha}^{-1}$, respectively. In contrast, the average minimum and maximum yield of different improved Teff varieties at farmers' field is 1.69ton ha ${ }^{-1}$ and 2.28ton ha ${ }^{-1}$, respectively (MoARD, 2010; Assefa et al., 2013).

\footnotetext{
${ }^{1}$ Injera is flat bread with a slightly spongy texture, originating from Ethiopia, which is made out of Teff flour. It is the national dish of Ethiopia.
} 
Accordingly, the Ethiopian government made massive interventions to increase crop yield in general and Teff yield in particular since 2010 (NPC, 2016; MoARD, 2010; AKLDP, 2015). Despite this, there is a high yield gap between the maximum possible yield obtained from research stations and the actual yield obtained from a farmer's field (Figure 2). There are several factors believed to contribute to this yield gap, such as moisture stress, shortage of modern inputs, low soil fertility, crop diseases, and pests (Aung, 2012). Moreover, neighborhood effects are the vital factors that contribute to Teff yield gap (Areal et al., 2012). This yield gap analysis indicates that farmers have an opportunity to narrow the gap by increasing their crop yield and gain the maximum possible yield if the determinant factors are appropriately addressed. The

level of Teff output would be enhanced either by increasing the level of input uses in the production or 'horizontal expansion' (Lobell et al., 2009), improving the efficiency of input uses in the production or 'improvement approach' (Lobell et al., 2009), introducing new technologies in the production or 'transformation approach' (Alene, 2003), or the combination of the those approaches.

Studies analyzed the technical efficiency of major cereal crops including Teff in Ethiopia regardless of the neighborhood effects (Ahmed et al., 2015; Abebe, 2014; Wollie, 2018; Tiruneh, 2013; Wassie, 2014; Gezahegn et al., 2006; Jemal et al., 2018a). Wassie, (2014) estimated the average technical efficiency of Teff production at 63.56\%, while Gezahegn et al. (2006) estimated it to be $80 \%$ and $83 \%$ for extension package program participant and non-participant of Teff farms in Ethiopia, respectively. These studies imply that without investing in any additional resources (i.e., using the existing technology); Teff production could increase by $17 \%$ to $36.44 \%$. The level of technical efficiency for Teff production is indicated to be lower than other cereal crops in Ethiopia (Gezahegn et al., 2006). However, these studies mostly focused on estimating the technical efficiency of Teff farms and its determining factors without considering the neighborhood effects (average neighbor farmers' socio-economic, institutional, and demographic characteristics).

\section{Spatial interaction between farmers and its implication}

Knowledge exchange is an important factor in boosting the efficiency of agricultural production. The Ethiopian government gave considerable attention to the role of the neighborhood effects and social learning in its policy framework and implemented an agricultural knowledge transfer 
approach mainly through extension service provision) since 2009 (Krishnan and Patnam, 2012). Farmers are influenced by the behavior and opinion of other people for choosing their immediate environment (Case, 1992). Besides, the interaction between farmers has been noted as an important component that affects agricultural production efficiency and technology adoption as documented in the applied economic literature (Pede et al., 2015; Villanueva et al., 2017; Tessema et al., 2016). The neighbor's influence is crucial in the estimation of technical efficiency and ignoring such effects may bias the estimation of important parameters. For instance, the level of education accomplished by farmers in a particular village could be relatively higher than in other villages. Similarly, a large number of farmers might adopt new technology and used inputs efficiently due to peer influences in the same village. Estimating the magnitude of the neighborhood effects is also highly relevant for crafting appropriate policy. For example, if the government wants to promote the adoption of new agricultural technology, then knowing the neighborhood structure might help the government to explicitly predict the size of externality linked with encouraging one farmer within the village to adopt the new technology. This externality might be neighborhood structure (farmer to farmer interaction).

The empirical literature on the estimation of the spatial interaction effect is concentrated in areas of human health, house price, and labor market (Anselin, 1988), but, less common in agriculture (Bockstael, 1996). Neighborhood effects are considered as spatial characteristics (Manski, 1993). Neighborhood effects are vital for enhancing agricultural production efficiency estimation (Areal et al., 2012) through knowledge exchange. Analysis of neighborhood effect in agricultural production efficiency indicates the existence of a correlation between the efficient farms and those of the neighboring farms (Areal et al., 2012). The neighborhood effect in technical efficiency can occur due to farmers copying the practices of the neighboring farmers or spatially closed farmers; especially when neighboring farmers earn a better profit and improve their livelihood. Neighbor farmers also highly interact with each other in terms of labor sharing, knowledge exchange, and information transfer on an agricultural production system (Areal et al., 2012; Villanueva et al., 2017; Dietz, 2002). Farmers copying their neighbor farmers' working culture and experience take a large part in the process of technology adoption and the creation of an efficient farm sector. Hence, examining neighborhood interaction helps to investigate the driver of technology adoption and technical efficiency of farm production (Maertens, 2009; Nivievskyi, 2009; Villanueva et al., 2017; Pede et al., 2015). Moreover, spatial factors can affect 
the production efficiency of farmers, and spatial analysis is a powerful approach to capture how an individual may behave similarly (Farrell, 1957; Manski, 1993).

Even though the neighborhood effects are believed to have an influence on agricultural production efficiency and use as a development actor in general and in Teff production efficiency in particular, there is a limited empirical study that analyzes the neighborhood effects on the technical efficiency of Teff farms in Ethiopia. This research is thus motivated by three important points: first Teff is a widely consumed cereal in Ethiopia, and it is a significant contributor to the country's export earnings, mainly through export of injera and flour because exporting Teff grain has been banned since 2006. Hence, Teff is considered as an economic cash crop and lifeblood of the majority of Ethiopian people. Second, the neighborhood effects on the technical efficiency of Teff farmers have not commonly assessed in the previous studies. Third, the previous studies used a cross-sectional dataset. Therefore, the main aim of this study was that estimate the level of the technical efficiency of Teff farms controlling for neighborhood effects using panel data estimation.

\section{Empirical model: model specification and estimation}

\subsection{Estimation of Teff production function}

The stochastic production frontier has been applied using a Maximum Likelihood (ML) Estimation approach through Stata 14. Based on Abedullah et al. (2009); Battese and Coelli (1992), the mathematical notation of the stochastic frontier production function for a timevarying efficiency is expressed as follows.

$\mathrm{Y}_{\mathrm{it}}=f\left(\mathrm{X}_{\mathrm{it}} ; \beta\right) \exp \left(\varepsilon_{\mathrm{it}}\right)$ where, $\exp \left(\varepsilon_{\mathrm{it}}\right)=\exp \left(\mathrm{V}_{\mathrm{it}}-\mathrm{U}_{\mathrm{it}}\right)$ and $\left.\mathrm{U}_{\mathrm{it}}=\mathrm{U}_{\mathrm{i}} \eta_{\mathrm{t}}=\mathrm{U}_{\mathrm{i}} \exp \left[-\eta_{(\mathrm{t}} \mathrm{T}\right]\right) \ldots \ldots(1)$

Where; $\mathrm{Y}_{\mathrm{i}}$ indicates Teff yield of $\mathrm{i}^{\text {th }}$ farmers $(\mathrm{i}=1,2, \ldots, 858)$ at the $\mathrm{t}^{\text {th }}$ period of observation $(\mathrm{t}=$ $2) ; f\left(\mathrm{X}_{\mathrm{it}} ; \beta\right)$ is a function of vector $\mathrm{X}_{\mathrm{it}}$ which represents a $1 \mathrm{x} \mathrm{k}$ vector of known functions for actual input quantities and other explanatory variables which applied by $i^{\text {th }}$ farmers at the $t^{\text {th }}$ period of observations; $\beta$ is a $\mathrm{k} \times 1$ vector of unknown parameters to be estimated; $E \mathrm{i}$ is the composite error term, which is defined as $\varepsilon_{\mathrm{i}}=\mathrm{V}_{\mathrm{it}}-\mathrm{U}_{\mathrm{it}}$. Where $\mathrm{V}_{\text {it }}$ is a random shock which is assumed to be independent and identical distributed (iid $\mathrm{N}\left(0, \sigma_{\mathrm{v}}{ }^{2}\right)$ ) random errors and independent of $\mathrm{U}_{\mathrm{it}}$; $\mathrm{U}_{\mathrm{it}}$ is non-negative random variables that are assumed to account for technical inefficiency in Teff production which often assumed that independent and identical distributed 
(iid) as truncations at zero of a normal distribution with mean $\mu$ and constant variance $\sigma_{\mathrm{v}}{ }^{2}(\mid \mathrm{N}(\mu$, $\left.\left.\sigma_{\mathrm{u}}^{2}\right) \mid\right) . \eta$ is an unknown scalar parameter related to the temporal pattern of inefficiency, and $\mathrm{T}$ is the end time. In this model, the non-negative farm effect $\left(U_{i t}\right)$ might decrease, remain constant or increase as $t$ increases if $\eta>0, \eta=0$, or $\eta<0$, respectively, If the value of $\eta$ becomes positive, the Teff farmers tend to enhance their level of technical efficiency over time. Moreover, if the $\mathrm{T}^{\text {th }}$ period observed for the $i^{\text {th }}$ Teff farmers, then $U_{i t}=u_{i}$ where, $i=1,2, \ldots, 858$. We estimated the production function per hectare-basis as Abedullah et al. (2009) because of its simple and straightforward interpretation of efficiency as opposed to per plot-based estimation (Battese and Coelli, 1992 and Hadri and Whittaker, 1999).

TE has been defined from a different perspective Battese and Coelli (1988); Färe et' al. (1985). But, I followed the definition of Battese and Coelli (1988), which means TE of a firm at a given period is the ratio of its mean production (conditional on its levels of inputs and firm effects) to the corresponding mean production if the firm applied its levels of inputs most efficiently. Its mathematical form, which is described by Hadri and Whittaker (1999) is:

$$
\mathrm{TE}_{\mathrm{i}}=\frac{\mathrm{Y}_{\mathrm{i}}^{*}}{\mathrm{Y}_{\mathrm{i}}} \approx \mathrm{TE}_{\mathrm{i}}=\frac{\mathrm{E}(\mathrm{Xi} \beta|\mathrm{ui}, \mathrm{Xi}|)}{\mathrm{E}(\mathrm{Xi} \beta|\mathrm{ui}=0, \mathrm{Xi}|)}=\exp \left(-\mathrm{U}_{\mathrm{i}}\right)
$$

Where, $\mathrm{Y}_{\mathrm{i}}{ }^{*}$ is defined as the average farmers' Teff yield (actual Teff yield) (Lobell et al., 2009) that is influenced by inefficiency factors $\left(\mathrm{u}_{\mathrm{i}}\right)$; $\mathrm{Y}_{\mathrm{i}}$ is defined as a potential yield or the maximum yield which could be reached by a crop in a given environments, as determined with plausible physiological and agronomic assumptions (Evans and Fischer, 1999). This implies that $Y_{i}$ does not influence by inefficiency factors. Besides, the mean TE of firms at the $\mathrm{t}^{\text {th }}$ time estimated as;

$$
\mathrm{TE}_{\mathrm{i}}=\mathrm{E}\left[\exp \left(-\eta_{\mathrm{t}} \mathrm{U}_{\mathrm{t}}\right)\right] \text { where, } \eta_{\mathrm{t}}=\exp [-\eta(t-T)] \text { and } 0 \leq \mathrm{TE}_{\mathrm{i}} \leq 1
$$

Here, the technical inefficiency is composed of two distinct components, such as, non-stochastic time component ( $\mathrm{t}-\mathrm{T})$ that is a time-varying component and common for all individuals and the other element is that individual stochastic component $\left(U_{t}\right)$ which is individual specific.

We followed the representation of Battese and Corra (1977) for likelihood function in terms of variance parameters who replaced $\sigma_{\mathrm{V}}^{2}+\sigma_{\mathrm{U}}^{2}$ with $\sigma^{2}=\sigma_{\mathrm{V}}^{2}+\sigma_{\mathrm{U}}^{2}$ and $\gamma=\sigma_{\mathrm{U}}^{2} / \sigma^{2}$; that means gamma indicates that the ratio of farm-specific variability to the total variability. If the value of $\gamma$ is positive and significant, then it indicates that farm-specific technical efficiency would be 
important to explain the total variability of Teff output produced, meaning that stochastic frontier model estimation is important to estimate the technical efficiency of Teff farm. Besides, the functional form of the Translog production function is:

$$
\ln Y_{i t}=\ln \beta_{0}+\sum_{j=1}^{5} \beta_{\mathrm{j}} \ln \mathrm{X}_{\mathrm{ijt}}+\frac{1}{2} \sum_{\mathrm{j}=1}^{5} \sum_{\mathrm{k}=1}^{5} \beta_{\mathrm{jk}} \ln \mathrm{X}_{\mathrm{ijt}} \ln \mathrm{X}_{\mathrm{ikt}}+\theta_{1 \mathrm{t}}+\mathrm{V}_{\mathrm{it}}-\mathrm{U}_{\mathrm{it}}
$$

Where, $U_{i t}=u_{i} \exp (\eta(\mathrm{t}-\mathrm{T})), \mathrm{X}_{\mathrm{i}}$ 's are the given inputs to produce Teff output (Table 1), $\theta_{1 \mathrm{t}}$ is the time trend, $V_{i t}$ is the random error term, and $U_{i t}$ is the non-negative random variables related to the technical inefficiency of individual farmers.

The technical inefficiency component $\left(\mathrm{U}_{\mathrm{it}}\right)$ assumes different distributional forms like halfnormal, exponential, truncated-normal, and gamma distributions. There is not any prior justification for choosing one distribution form over the others, even if those distributional forms have their own assumption. The choice of distributional specification for the technical inefficiency element is a matter of computational convenience because of the estimation of some frontier model automated in some software packages but not in others (Coelli et al., 2005). As like Battese and Corelli's time-varying model Battese and Coelli (1992), truncated normal distribution of technical inefficiency components have been considered for this study.

\subsection{Estimations of neighborhood effects on Technical efficiency}

The classical econometric models like Ordinary Least Square regressions are unbiased but inefficient in the presence of spatial dependency due to the presence of spatial autocorrelation (Anselin, 2001). Spatial dependency refers to the situation where the dependent variable or error term at each location correlated with the observations on the dependent variable or values of error term at other locations. It is expressed mathematically as $\mathrm{E}[\mathrm{yi} ; \mathrm{yj}] \neq 0$ or $\mathrm{E}[\varepsilon \mathrm{i} ; \varepsilon \mathrm{j}] \neq 0$ for any neighboring locations $\mathrm{i}$ and $\mathrm{j}$ as opposed to the null hypothesis of homoskedastic or uncorrelated errors (i.e H0: $\rho=0$ ) where, $\rho$ is the spatial autoregressive coefficient (Anselin, 1990). Hence, the inferences based on $\mathrm{t}$ and $\mathrm{F}$ statistics will be misleading, and goodness of fit based on $\mathrm{R}^{2}$ will be incorrect. As a result, a spatial econometric model that is more comparable to spatial dependency's estimation has been developed (Anselin, 2003). Among these, many researchers currently apply spatial lagged explanatory (SLX) model, which is the extension of OLS, but, SLX model includes the neighbors' characteristics by weighting their connectedness into the model estimation. 
Basically, four common spatial econometric models are presented and commonly applied in the existing literature (Anselin et al., 1996). These are; spatial lag or autoregressive lag model (SARM), spatial autoregressive error model (SEM) and the combination of SARM, and SEM (SARMA or ARAR). These models have a restriction on including the lag of independent variables or neighbors' characteristics to the model specification; hence, these models do not predict the neighborhood effects in terms of neighbors' characteristics. however, the SLX model is a better model estimation to identify the neighborhood effects by making the spatially lagged explanatory variables as WX among the observations who spatially related (Gibbons and Overman, 2012; Halleck Vega and Elhorst, 2015). WX is the exogenous interaction effect among the independent variables or it is the neighbor's weighted average farm characteristics. Therefore, the SLX model was used for this study to estimate the neighborhood effects on the technical efficiency of Teff farms in the study area. Based on the SLX model functional form, a farmer's outcome $Y_{i}$ is affected by his own characteristics (direct effects) and the average weighted farm characteristics of his neighbor groups $\mathrm{X}_{\mathrm{j}}$ (neighborhood/indirect effects). The mathematical notation of the SLX model is:

$$
\mathrm{U}_{\mathrm{it}}=\alpha \ell_{N}+\mathrm{X}_{\mathrm{it}} \beta+\theta \mathrm{WX} \mathrm{jt}_{\mathrm{t}}+\varepsilon_{\mathrm{it}}
$$

Where; $\mathrm{U}$ is the $(\mathrm{NT} \times 1)$ column vector of technical inefficiency score of individual farmer $\mathrm{i}$ at time $\mathrm{T} ; \ell_{\mathrm{N}}$ is the $\mathrm{N} \times 1$ vector of which associated with the constant term parameter $\alpha ; \mathrm{X}_{\mathrm{i}}$ is the $(\mathrm{NT} \times \mathrm{K})$ matrix of the listed explanatory variables of individual $\mathrm{i} ; \beta$ is the $\mathrm{K} \times 1$ vector with parameters of the independent variables to be estimated; $\mathrm{WX}_{\mathrm{j}}$ is the neighbor's (individual $\mathrm{j}$ ) weighted average socioeconomic characteristics; W indicates the spatial weight indicates farmer's social connectedness or an indication of knowledge transmission between neighbor farmers; $\theta$ is also the $\mathrm{K}$ x 1 vector with the parameter of spatially lagged independent variables to be estimated; $\varepsilon$ is an $(\mathrm{N} \times 1)$ column vector of the error term which independently and identically distributed with zero mean and constant variance.

From equation (5), $\beta$ and $\theta$ are the direct and indirect effects of the independent variables, respectively. A direct spatial effect is defined as the marginal impact of a change to one explanatory variable in the $\mathrm{i}^{\text {th }}$ farmer at $\mathrm{t}^{\text {th }}$ period on the dependent variable of the farmer himself ( $\mathrm{t}^{\text {th }}$ farmer). But, an indirect spatial effect is defined as the marginal impact of a change to one 
explanatory variable in the $\mathrm{i}^{\text {th }}$ farmer at $\mathrm{t}^{\text {th }}$ period on the dependent variable values of $\mathrm{j}^{\text {th }}$ farmer. As a result, the spatial panel lag of independent variables (SLX) model specification is:

$$
U_{i t}=\sum_{z=1}^{12} \beta_{\mathrm{z}} \mathrm{X}_{\mathrm{izt}}+\sum_{\mathrm{k}=1}^{6} \theta_{\mathrm{k}} \mathrm{WX}_{\mathrm{jkt}}+\mathrm{c}_{i}+\mathrm{u}_{\mathrm{it}}
$$

Where $c_{i}$ is an individual unobserved heterogeneity effect and $u_{i t}$ is a normally distributed error term. In the RHS of equation (6), the first and second summations show the value of farmers own characteristics and average weighted neighbors' characteristics (neighborhood effects).

\subsection{Controlling for unobserved heterogeneity $\left(c_{i}\right)$}

Unobserved heterogeneity indeed happens in any survey data. However, panel data allows separating the time-invariant individual effect (unobserved heterogeneity) from the time-variant random shocks and better chance to control for it. Thus, the assumption that the independent variables should be uncorrelated with the unobserved heterogeneity $\left(\mathrm{c}_{\mathrm{i}}\right)$ must be needed to acquire the consistent and unbiased result of the estimates. We applied the Correlated Random Effect (CRE) estimation for the spatial lagged explanatory model based on Mundlak (1978) and Chamberlain (1984) cited by Woldeyohanes et al. (2017) to control the unobserved heterogeneity. The CRE model can relax the assumption of independence between unobserved heterogeneity $\left(\mathrm{c}_{\mathrm{i}}\right)$ and independent variables. Like the Fixed Effect model, the CRE model allows the correlation between the individual unobserved heterogeneity and independent variables across the time. So, the functional form of unobserved heterogeneity through CRE model estimation is:

$$
c_{i}=\varphi+\gamma \bar{X}_{l}+r_{i}, \bar{X}_{l}=T^{-1} \sum_{t=1}^{T} X_{i t}
$$

Where, $\bar{X}_{l}$ is the time average for all time-variant independent variables from equation (6); assuming this time average value is constant for each household in each year; however, it differs across households. The variable $\varphi$ and $\gamma$ are constants, $r_{i}$ is a normal error that independently distributed with a zero mean and constant variance $\left(\mathrm{r}_{\mathrm{i}} \mid \mathrm{X}_{\mathrm{i}} \sim\right.$ Normal $\left.\left(0, \delta^{2}{ }_{\mathrm{r}}\right)\right)$ raised from the unobserved individual effect.

Once we specified the unobserved heterogeneity, the mathematical form of the CRE spatial lagged explanatory model is: 


$$
U_{i t}=\varphi+\sum_{z=1}^{12} \beta_{\mathrm{z}} \mathrm{X}_{\mathrm{izt}}+\sum_{\mathrm{k}=1}^{6} \theta_{\mathrm{k}} \mathrm{Z}_{\mathrm{ikt}}+\gamma \overline{X_{i}}+r_{i}+\mathrm{u}_{\mathrm{it}}
$$

Where $\varphi$ is an intercept, and $r_{i}$ and $u_{i t}$ are error terms.

The main motivation to use CRE model instead of the random effect model is that (1) CRE model provides a technique to include time-invariant independent variables as effective as Fixed Effect model, (2) CRE model allow controlling time-invariant heterogeneity using the average of all time-variant independent variables without encountering the incidental problem. Hence, it is possible to control the unobserved heterogeneity effects like Fixed Effect model estimation (Wooldridge, 2010).

\subsection{Definition of spatial neighbors and spatial weight matrix}

The fundamental identification problem of spatial neighbors is reflection problems, which coined by Manski (1993). Manski described three types of effects in the analysis of neighborhood effects. The first one is that the behavior of his neighbor group influences the endogenous effect, which comes from an individual farm's behavior. For example, poor farmers might live in the same neighborhood; rather, they will live with rich farmers. The second effect is that exogenous or contextual effect, which shows the tendency of an individual Teff farm to behave in some way as a function of the exogenous characteristics of his neighbor group. For instance, the neighbor groups of the farm "i" illiterate; hence, farm " $i$ " might observe low adoption of modern agricultural inputs due to lack of knowledge and technical constraints of input use. The third effect in neighborhood study is that correlated effect, which illustrates the conditions in which individuals in the same neighborhood group tend to behave similarly due to similar characteristics they have or face similar institutional and environmental environments. For instance, bad weather, poor neighborhood (poor farmers might have transmitted lower cognitive farm skills), weak extension provision, and so forth.

Studies examined neighborhood effects on agriculture production at a single farm and aggregate level, but they differ in the identification approach of neighbor groups and spatial weight. Some of them defined neighbor groups based on the village/municipality of the farmer's dwelling (Saint-Cyr et al., 2019 and Holloway et al., 2002); others used a cut-off or threshold distance (Villanueva et al., 2017; Tessema et al., 2016; Adjognon and Liverpool-Tasie, 2015; Storm and 
Heckelei, 2015; Lapple and Kelley, 2015; Areal et al., 2012; Krishnan and Patnam, 2012; Schmidtner et al., 2012).

According to the Ethiopian perspective, farmers are behaving with similar lineage or blood connections, and strong social interconnection tends to cluster in the same area. Thus, the social distance can reasonably be estimated by geographical distance. In principle, there is a possibility that a farmer's choice of his/her neighbor or social group could be endogenous. That means people might non-randomly select their neighbors based on their preferences, income, and the availability of alternative housing; in this case, the estimation could be more complicated. However, in our study, we used geographic neighbors; this means that neighbor groups defined in terms of geographical proximity; it will appear the neighbor choice is exogenous because the geographical location of the farmers will not influence by any external bodies, rather it is random. In Ethiopia, a governmental and non-governmental organization that works in the agriculture sector promotes various new agricultural technologies like fertilizer application, row sowing technology, improved seed, wee management technology at a different level of administrative units (village, district, zonal, and regional levels). These institutions organize farmers' field visits, training, experience sharing, and workshops in the aforementioned administrative levels to disseminate knowledge from efficient farmers to their fellow farmers. Moreover, Enumeration Areas are typically located in the village and the agricultural activities are strongly adapted to the local micro-relief, so it is possible to observe different modes of production and mixes of crops in areas just a few kilometers away from the other. Hence, in a nutshell of these truths and the available geographical make of our data, we adopted the Enumeration Areas $\left(\mathrm{EA}^{2}\right)$ to define the neighbor groups; meaning that farmers who belong to the same EA considered as a neighbor group and outside the EA who didn't consider as neighbors; it

\footnotetext{
${ }^{2}$ EA stands for Enumeration Area, which is a unit of land delineated for the purpose of enumeration housing units and population without omission or duplication through geographical distance. EA usually consists of 150 to 200 households who belong to the same rural areas and 150 to 200 housing units in urban areas. Kebelle is the smallest unit of administrative unit in Ethiopia. An EA should be related to an urban or a rural Kebelle if an EA may be equal to rural Kebelle if the number of the households in the rural Kebelle is less than or equal to $150-200$; and is equal to urban Kebelle in urban area if the number of housing units in the urban Kebelle is 150 - 200 or an EA may be a part of an rural Kebelle or urban Kebelle, but, its delineation can't extend outside the border of the Kebelle (CSA, 2018b). The latitude and longitude for each EA is available in the dataset.
} 
is the same concept with Saint-Cyr et al. (2019) and Holloway et al. (2002). The Saint-Cyr and Holloway defined the neighbor group based on the municipality of farmer's dwelling, meaning that when farmers live in the same municipality, they are neighbors, and outside the municipality, they did not consider as a neighbor (Saint-Cyr et al., 2019; Holloway et al., 2002). Besides, the definition of neighbor is as a binary choice by taking a value of 1 if the households belong to the same EA, and 0 if the farmers belong to outside the EA. Alongside this logic, if farmers who belong to the same enumeration area, then they have the same spatial weight value. Therefore, we had 162 EA for 858 Teff producing farmers; on average, there are five farmers considered as neighbors within an EA. These number of neighbors are acceptable and applied in the previous studies (Krishnan and Patnam, 2012 and Tessema et al., 2016). In this approach, it is not necessary to compute spatial weight value independently; rather we computed the average farm characteristics by EA excluding the own value of the farm $i$ to get the average value of the neighbor's farm characteristics $\left(Z_{i t}\right)$ within the EA. Here, all neighbors are equally weighted. Mathematically, the equation of $Z_{\mathrm{it}}$ is as follows.

$$
Z_{i t}=\frac{\left[W_{i t}\right] *[N x P]}{\sum W_{i t}}
$$

Where, $Z_{i t}$ is the average value of the neighbor's farm characteristics, $[N \times P]$ is the dimensional matrix of the explanatory variables that want to estimate in the model, $\mathrm{W}_{\mathrm{it}}$ is a row vector of the spatial weight matrix that defined earlier.

\subsection{Data}

This study is applied to the Ethiopian Socioeconomic Survey (ESS) panel data collected by the Ethiopian Central Statistical Agency (CSA) and the LSMS-ISA project of the World Bank. The survey is representative at the regional level for the most populous regions; Amhara, Oromia, SNNP, and Tigray. Also, this survey covered the small regions, such as; Afar, Benishangul Gumuz, Dire Dawa, Gambella, Harari, and Somali regions by producing the "other region" category for the combination of such smaller regions. The survey followed two-stage sampling approach. First, select the primary sampling units that are Enumeration Areas when regions of the country are considered as strata. Second, the participant households were selected using proportional random sampling technique in each EA. 
The survey began in 2012; about 290 and 43 EAs were selected from the rural and small towns, respectively. About 333 EAs were conducted and 3,969 households interviewed from these EAs. The survey was extended to 433 Enumeration Areas in the second and three-wave of the survey (2014 and 2016) to make inferences to the population of urban households. Thus, about 290, 43, and 100 EAs were selected from rural areas, small towns, and large towns, respectively. Thus, there were 433 EAs were addressed in the second and third wave of the survey (2014 and 2016). About 3,776 households re-interviewed with a 5\% attrition rate, or successful follow-up rate of $95 \%$ in the second wave of the survey (2014). In the third wave of the survey (2016), about 3,699 households were re-interviewed with a 7\% attrition rate. For this study, the 2014 and 2016 survey rounds are employed because these survey rounds contain sufficient variables of interest. Hence, the final balanced panel dataset contained sufficient data on the 858 Teff producing households at 162 EAs in five regions (Amhara, Oromia, SNNP, Tigray, and Benishangul Gumuz) (Figure 4). However, Afar, Dire Dawa, Gambella, Harari, and Somali regions are excluded from the analysis because there are no Teff producing farmers resided in these regions.

\section{Results and Discussions}

\subsection{Test specification}

Multiple tests have been applied before proceeding to stochastic production frontier and panel model estimation.

First, the variance inflation factor (VIF) was made for multicollinearity problems. Hence, the value of VIF for all variables that used for model estimation was below 10 which indicates that there is no severe problem of multicollinearity problem (Table 6). Also, Robust standard errors are applied to obtain unbiased standard errors of model coefficients under heteroscedasticity.

Second, the likelihood ratio test has been applied to test the inefficiency components present or not in the Teff production function. This is made to decide whether the classical average production function (OLS) best fits the dataset as compared to the stochastic frontier Teff production function. The likelihood ratio test assuming the null hypothesis is that no technical inefficiency $\left(\mathrm{H}_{0}: \gamma=0\right)$. Hence, the likelihood ratio test statistics showed that the value of the likelihood ratio $(\mathrm{LR})$ is $\left(\mathrm{LR}=-2\left(\mathrm{LH}_{0}(\right.\right.$ for OLS $)-\mathrm{LH}_{1}($ for translog $\left.)\right)=-2(1783.1768-$ $2078.0198)=589.686$. This value exceeded the critical values $\chi^{2}(5 \%, 1)$ value of 3.841 at a $5 \%$ level of significance (Table 2). As a result, the null hypothesis of the likelihood ratio test was not 
accepted, meaning that there are statistically significant inefficiency components in the dataset. Therefore, the stochastic frontier production function was an appropriate model estimation for the available dataset.

Third, the log-likelihood ratio test has been employed to select an appropriate functional form for the dataset. The most common functional forms of production functions are Cobb-Douglas and Translog production function. The null hypothesis for this test is that all coefficients of the interaction terms in Translog specification are equal to zero. The calculated log-likelihood ratio $\left[\mathrm{LR}=-2\left(\mathrm{LH}_{\mathrm{CD}}-\mathrm{LH}_{\text {Translog }}\right)=-2(1911.4430-2078.0198)=333.1536\right]$ is equal to 333.1536, and the critical value of $\chi 2$ at 19 (for the variables of translog function) degree of freedom and $5 \%$ significance level is 30.144 (Table 2). Therefore, the null hypothesis was not accepted, implies that the Translog functional form adequately represents the data. Therefore, the Translog production function was employed to estimate the technical efficiency of the sample households in the study area.

Fourth, the test for the technical inefficiency factors is not affected by the neighborhood and socioeconomic variables incorporated in the inefficiency model $\left(\mathrm{H}_{0}=0=1=2=\ldots=25=0\right)$ was applied. The calculated likelihood ratio value of 589.686 was bigger than the critical value of 37.652 at 25 degrees of freedom (Table 2). This indicates that the null hypothesis $\left(\mathrm{H}_{0}\right)$ was not accepted at five percent of the significance level. Therefore, the result showed that all those explanatory variables included in the model were simultaneously explained the source of technical efficiency differences among the sample Teff producing farmers.

Fifth, the correlation between $\mathrm{X}_{\mathrm{it}}$ and $\mathrm{Z}_{\mathrm{it}}$ variables has been checked. The correlation coefficients reported in (Table 5) revealed that the relationship between $X_{i t}$ and $Z_{i t}$ variables is commonly weak but non-zero Hence, the result of this relationship leads to estimate the impact of $\mathrm{X}_{\mathrm{it}}$ and $\mathrm{Z}_{\text {it }}$ independently.

Sixth, the Hausman test has been applied to select the appropriate panel model estimation (Fixed Effect model versus Random Effect model). Thus, the null hypothesis is that the Random Effect model was not accepted (Table 7). This implies that the Fixed Effect model is an appropriate model estimation. However, the Fixed Effect model is not able to estimate time-invariant independent variables like gender, education of the household head, market distance and so forth. 
As a result, Correlated Random Effect model is more suitable to estimate the impact of both time-variant and time-invariant independent variables on the level of technical efficiency of Teff production.

\subsection{Descriptive statistics}

The summary statistics of the inputs employed for ML estimation and independent variables used for CRE estimation are explained in the table (1).

The average Teff yield from the sample households was 1.21 ton $\mathrm{ha}^{-1}$. Five inputs are considered in the Teff production function. The average value of seed, mineral fertilizer, labor, and land are $30.77 \mathrm{~kg} \mathrm{ha}^{-1}, 86.29 \mathrm{~kg} \mathrm{ha}^{-1}, 154.781 \mathrm{MD} \mathrm{ha}^{-1}$, and $1.24 \mathrm{ha}$, respectively. The sampled households have two oxen in number. The typical small farm size in Ethiopia is 0.9ha (Rapsomanikis, 2015). Generally, about $80 \%$ of the total farm output, in Ethiopia, relies on animal traction and human power instead use of tractor mechanization (CIMMYT, 2014). Farmers, who do have less than one ox, use a different approach for plowing their farm plot, such as; renting ox, using horse, cow or donkey, digging, using borrowed oxen. The minimum value of mineral fertilizer was zero because all farmers did not apply mineral fertilizer in their Teff farm. Besides, about $25 \%$ of the sample farmers did not apply mineral fertilizer in their Teff production. On the topic of labor perspective, Teff production is a more labor-intensive farming practice Bekabil et' al. (2011) cited by Crymes (2015).

Age of the household head: the average age of the sample household head is 50 years, with the minimum and maximum years of age of 22 and 99, respectively. Besides, male-headed farmers account for $87 \%$ of the whole sampled farmers; this indicates that about $87 \%$ of the controlling, managing, and undertaking of agricultural resources are male responsibilities. The average distance from the nearest market is approximately 67.75 kilometers, with a standard deviation of 42.09 .

Level of education of the household head: the average years of schooling for the household head are two with a minimum and maximum of 0 and 13 years of schooling, respectively. About $55.13 \%$ of the sampled farmers are illiterate or have zero schoolings; the main reason when farmers stated during the survey was that lack of perception, the unwillingness of the family and 
uneducated family background. In addition, the average level of education of the household head within the Enumeration Areas is two years of schooling.

Improved seed application: this is measured as a dummy variable with one for use of improved seed and zero otherwise. About $20 \%$ of the sampled farmers used improved seed; it indicates that about $80 \%$ of the sample farmers used traditional seed due to different reasons such as unavailability of improved seed, high price, low advice from extension officers and input suppliers, as well as their preference of using traditional seed. The primary seed sources for Teff production are relatives, neighbors, village development committee members, village headmen, and traditional authority. Moreover, about $31 \%$ of the neighbor farmers within the enumeration areas used improved seed.

Mineral fertilizer usage: this is also measured as a dummy variable with one for use of mineral fertilizer and zero otherwise. About $75 \%$ of the sample farmers applied mineral fertilizer in their plots; while the remaining $25 \%$ of the sample farmers did not use mineral fertilizer due to reasons such as; high price, lack of money, in-availability of supply, lack of credit, skeptical (disbelieving) of the outcome, and ignorance (lack of knowledge). There are different fertilizer suppliers in the country, such as; government organization, private organization, and merchants, however, the leading supplier of mineral fertilizer is a government organization, which has drawn their sectors from federal to the lowest level of administration (Kebelle) to deliver and fulfill the demand of the rural farmers. Likewise, about $73 \%$ of the neighbor farmers within the enumeration areas applied mineral fertilizer.

Teff planting methods: there are two major Teff planting techniques in Ethiopia, such as; broadcasting and row planting techniques. The majority of the sample farmers used broadcasting planting techniques. However, a small fraction of sample farmers (12\% of the sample farmers) practiced row planting techniques. The Teff row planting technique has recently been emerged and has already created a dilemma. In one side; Teff row planting helps to reduce seed rate and contribute to production increment (Vandercasteelen et al., 2013 and Vandercasteelen et al., 2014), on the other side; Teff row planting demands vast number of labor, time, and technical difficulty (Vandercasteelen et al., 2014). Hence, farmers prefer to use the broadcasting Teff 
planting techniques to reduce the related risks. Furthermore, about $12 \%$ of the neighbor farmers within the enumeration areas used row planting method, averagely.

Extension service participation of the household head: this is measured as a dummy variable with one for participate in extension service provision and zero otherwise. About $56 \%$ of the sampled farmers participated in extension service provision. Likewise, about $54 \%$ of the neighbor farmers within the enumeration areas participated in extension service provision.

Community participation of the household head: this is measured as a dummy variable with one for participate in the communal activities and zero otherwise. It is one of the key elements for enhancing farm efficiency through transmitting information from efficient farms to their fellow farmers within the EA. According to the descriptive statistics, about $76 \%$ of the sampled farmers participated in community activities; on the other hand, about $24 \%$ of the sampled farmers did not participate in community activities. The main activities that have been undertaken in the respective community are terracing, planting a tree, preparing water harvesting pits, trenches, road and bridge construction, sewerage construction, and wire mesh (Gabion). Hence, to participate in such types of community activities, farmers might have a high probability of adopting better experience from their peers regarding farm activities. Moreover, about $74 \%$ of the neighbor farmers within the enumeration areas have participated in the communal activities, averagely.

Soil fertility of the plot: it is the relative soil fertility status of the sampled farmers' plots, so, it is a dummy with one for fertile and zero otherwise. About $38 \%$ of the soil fertility status of the farmers' Teff plot is good; the remaining $62 \%$ is either poor or has a moderate level of soil fertility.

\subsection{Results of Maximum Likelihood Estimation}

The results of the maximum likelihood estimation of the translog production function are depicted in table (2). Among the estimated inputs; seed, labor, land, and mineral fertilizer are positively significant at $1 \%$ and $5 \%$ level of significance. The seed has more impact on the efficiency of Teff farms than other inputs. The second, third, and fourth influential inputs in Teff production are labor, land, and mineral fertilizer application, respectively. However, surprisingly, the input variable, oxen, is not significant in the model. 
Based on the theory 0of the stochastic frontier approach, the verification of gains or losses of the efficiencies was measured through time trends. Hence, this time trend is observed by the component of $\eta$, which is positively significant at a $5 \%$ level of significance; this indicates that the technical inefficiencies of the sampled Teff farmers are decreasing over time.

The coefficient of the mean-variance $(\mu)$ related to inefficiency components is statistically significant. This shows that the normal truncated distribution of technical inefficiency is appropriate over the half-normal distribution. The value of gamma $(\gamma)$ is statistically and positively significant, which indicates that the variance of technical inefficiency or farm-specific variability component explains approximately about $21.6 \%$ of the total composed error variance of the Teff production function. So, including technical inefficiency or farm-specific variability is important to explain the overall variability of Teff production.

Another important parameter in the model estimation is the time trend $(\mathrm{t})$; its coefficient is positively significant, which indicates that there is technological progress in Teff production. This technological progress may demand improved teff varieties, row planting, fertilizer application, small-scale farm mechanization like a hand-held motorized tiller, improved oxen driven plough, and a small tractor through time. This finding was also supported by (Berhane, 2014). However, small-scale farm mechanization in Ethiopia is too infant, and only a small fraction of farmers (farmers' union) use such types of equipment (Berhane, 2014).

The interaction of time trend and the other five inputs also indicates a technological process. Theoretically, the interaction or joint effects tell that how two or more covariates work together to impact the dependent variable; it also provides a better understanding and representation of the relationship between the covariates and dependent variable (Lavrakas, 2008). Besides, the coefficients of the interaction of seed usage with time are positively and statistically significant, which shows that the technological progress shifts directly with the seed usage, meaning that technological progress tends to enhance the use of Teff seed. So, it is likely to increase the demand for improved Teff seed to increase the Teff output over time. However, the coefficients of the interaction of labor with time and the interaction of mineral fertilizer with time are negatively significant, which indicates that the technological progress swings inversely with labor and mineral fertilizer, meaning that technological progress tends to diminish the utilization 
of labor and mineral fertilizer. When there is this technological progress in Teff production, then the farming activities will turn out to capital intensive than labor-intensive; it also tends to increase the use of organic fertilizer than mineral fertilizer.

\subsubsection{Distribution of technical efficiency scores and yield gap analysis due to technical inefficiency}

The distribution of technical efficiency of Teff farms is depicted in figure (7). Figuratively, the technical efficiency scores of the Teff farmers lay from a minimum of $67.9 \%$ to a maximum of 92.5\%; this means the technical inefficiency level varies from $7.5 \%$ to $32.1 \%$. Besides, the average technical efficiency of Teff production within the sampled farm is $78.5 \%$. Most of the Teff farmers had a lower technical efficiency score; which indicates that the distributions of the technical efficiency scores is skewed to the left. The majority $(84.7 \%)$ of the sample Teff farmers have technical efficiency scores less than or equal to $80 \%$. On the other side, about $15.3 \%$ of the sample Teff farmers have a technical efficiency score above $81 \%$; this implies that farmers have the likelihood to increase Teff production by $19 \%$.

Yield gap is estimated as "the difference between the potential yield and the average farmers' yields (actual yield) over the time specified a spatial and temporal level of interest" (Lobell et al., 2009). The individual farmer's technical efficiency and their actual Teff yield allowed me to estimate the possible maximum level of Teff yield that produces through efficient use of the existing level of inputs and technology. Hence, the potential Teff yield of the sampled Teff farmers was estimated by dividing the actual Teff yield of individual farmers to the predicted technical efficiency scores from the stochastic frontier model. Then, the Teff yield gap was estimated by subtracting the technically full efficient Teff yield and actual/observed Teff yield. The graphical Teff yield gap analysis is reported in the figure (5).

As depicted in the table (3), the average Teff yield gap was 0.3 ton $\mathrm{ha}^{-1}$. This yield gap illustrates that the sample farmers in Ethiopia were producing, on average, about 0.3ton ha ${ }^{-1}$ lower Teff yield than their maximum potential yield in the given years. Besides, farmers tend to increase Teff yield on average by 0.3 ton $\mathrm{ha}^{-1}$, in the short run, at the current level of input use and technology by eliminating the technical inefficiency factors. Farmers have a chance to increase Teff yield under the current level of input use and farming practices because the gap between the 
actual and potential Teff yield is coming from the technical inefficiency component (controllable component). Generally, the argument behind this yield gap analysis is that farmers can reduce this yield gap if they use their inputs efficiently.

\subsubsection{The elasticity of inputs of Teff production}

The predicted elasticity of Teff output for land, labor, fertilizer, and seed is $0.121,0.285,0.008$, and 0.431 , respectively (Table 2). This elasticity indicates that with a one percent increase in the use of farmland, labor, mineral fertilizer and seed, then, the hectare of farmland, the number of labor, kilograms of fertilizer, and kilograms of Teff seed lead to 0.121, 0.285, 0.008, and 0.431 percent in the level of Teff output, respectively. Unlike the prior hypothesis, the number of oxen is insignificant in the model; the possible reason could be farmers may use rented and/or shared animals. Also, in some regions of the country, particularly in Oromia and SNNP, farmers focus on the rearing of livestock. The result shows that seed and labor are the super imperative inputs in the efficiency of Teff farms, meaning that the increment of the labor force and for Teff production make relatively significant contributions to the Teff output increment. Besides, the sum of elasticity of all significant inputs $(0.845)$ is greater than one, meaning that Teff production function exhibits decreasing returns to scale. So, as a percent increase in all inputs proportionally would increase the total Teff production by less than $1 \%$. This study coincides with Wassie (2014) who estimated the returns to scale to be $0.97 \%$ and oppose Abebe (2014) who found the return to scale to be $1.396 \%$ and in the study of technical efficiency of Teff production in different regions of Ethiopia.

\subsection{The determinant factors of technical efficiency of Teff farms}

Once the level of technical efficiency of Teff farms is measured and information regarding the existence of technical inefficiency in Teff farms is obtained, the potential sources of technical inefficiency factors were identified. The main sources of technical inefficiency of Teff farms are farmer's own characteristics, their average neighbor's characteristics, or from both by taking the level of technical inefficiency scores as a dependent variable. The result of the correlated random effect (CRE) estimation of the spatial lagged explanatory model is reported in the table (5). 


\subsubsection{Farmer's own characteristics that affect the technical efficiency of Teff farms}

Among the estimated independent variables, about six farmers own farm characteristics have statistically significant effects on the technical efficiency of Teff farms such as gender, education, age, and community participation of the household head and family size.

Gender of the household head has a positive effect on the technical efficiency of Teff farms; this shows that the male-headed Teff farmers are more efficient technically than female-headed farmers. The reason might be female-headed farmers facing a workload in both home and field activities than male-headed farmers. Abebe also found the same result that the gender of the household head and technical efficiency have a direct association (Abebe, 2014).

The education level of the household head has a positive association with the technical efficiency of Teff farms. Education considered an indicator of having better managerial skills, input access, and adopt new technology in their farm operations as quickly as possible. Therefore, farmers who have more schooling are more technically efficient in Teff farming. This finding is also supported by Abebe (2014) and Wassie (2014).

Age of the household head has a positive effect on the technical efficiency of Teff farms. As the prior expectation of the hypothesis, the age of the household-head is one of the determinant factors of the technical efficiency of Teff farms. Age is considered as a proxy of farm experience. Hence, farmers who have more years of experience are expected to be more technically efficient. This result confirmed with Wassie (2014). Apart from this logic, age has a parabolic effect on agricultural technology adoption by taking the assumption of old farmers' fear to take a risk in their farm operation beyond a turning point or optimum age (Fikadu et al., 2017).

Family size is another factor in the technical efficiency of Teff farms. We found that there is a positive association between the technical efficiency of Teff farms and family size; this shows that households who have a large number of family size become more efficient than the households who have small family size. The reason would be Teff farming is labor-intensive; hence, households have a likelihood of getting abundant labor supply during Teff cultivation if they have large household sizes. This result also in line with Abebe (2014). 
The level of participation of the household head in different communal activities like making soil and water conservation practices (soil-bound, planting trees), and community social meeting is an alternative platform to transmit farm knowledge and information. Hence, community participation and technical efficiency have a positive correlation between each other, meaning that farmers who participate in community activities are more efficient than others who do not participate. This finding is also consistent with previous studies Solís et al. (2007) who found a positive association between technical efficiency and soil conservation practices in Central America and Abebe (2014) who also found the same result, that is, conservation practices and technical efficiency have a direct association between each other in Ethiopia.

Soil fertility of the Teff plot is statistically and significantly affect the technical efficiency of Teff farms in the study area. This indicates that the farmers who have a good fertile plot are more efficient that the farmers who have poor soil fertility of the Teff plot.

Teff planting approach also has a positive effect on the technical efficiency of Teff farms; this shows that farmers who applied row planting methods are more efficient than the farmers who used broadcast Teff planting approach. As explained in the descriptive analysis of this study, row planting of Teff is a recent technology that has a positive contribution to the Teff yield increment. Row planting of Teff has a positive effect on yield increment, which increases from $2 \%-22 \%$ at farmers' field and 26\% at Farmers Training Center (FTC) (Vandercasteelen et al., 2013).

Surprisingly, extension service involvement of the household head was found to be insignificant. The main principle of the extension service program is that technical support delivery to farmers how the farm technologies implemented to improve crop productivity. The reason could be related to the quality of the extension service delivery; it might be a poor quality of service delivery system. This finding is supported by the study of Wassie (2014). Wassie argued that the quality of extension service delivery is not good as its expected goal, while extension service providers (Development Agents) are actively engaged in various tasks than supporting the farmers regarding farm operation. Also, Gufera argued that the effectiveness of the extension services in Ethiopia is very low because the development agents are insufficiently trained and 
involved in multiple activities (Dufera, 2018). Therefore, the involvement of the farmers in the extension service program does not influence their Teff farm efficiency.

\subsubsection{The neighborhood effects on technical efficiency of Teff farms}

As depicted in the table (5), the neighborhood effects clearly influence the technical efficiency of Teff farms; which is significantly higher in the average weighted neighbors' improved seed use. Also, we can see that the omission of neighborhood effects might affect the inferences on the estimation of the parameters of the SLX model. The significant effects on the estimates of the parameters of the SLX model show how the omission of neighborhood effects might affect the inferences.

The average weighted neighbor's mineral fertilizer application has a positive impact on the technical efficiency of Teff farms. The result indicates that when farmers use mineral fertilizer in their farm plot, then their neighbor farmers will capture new knowledge and try to practice in their farm operation without waiting for extension experts and input providers. Thus, the farmer's technical efficiency influenced by their neighbor farmers who vigorously apply mineral fertilizer for teff farms within the neighbor group.

The average weighted neighbor's community participation level is also statistically significant and has a positive effect on the technical efficiency of Teff farms in Ethiopia. Meaning that when the neighbor farmers are actively participating in the community activities, farmers will get new information for the farm operation, which turned out to transmit the information to their peer groups. So, based on our findings, the average community participation of the neighbor farmers has a positive influence on the technical efficiency of the Teff farm within the neighbor group.

The average weighted neighbor's improved seed usage has a significant and positive effect on the technical efficiency of Teff farms, which implies farmers' use of improved seed is significantly affected by the use of his/her neighbors. Farmers build an ability to use improved seed due to the influence of their neighbors; even they will not wait for the seed provider institutions. In the Ethiopian context, there is a strong traditional practice to exchange seed between spatially close farmers in terms of either in-kind or in-cash (Ademe and Fikadu, 2018). 
The average weighted neighbor's Teff planting approach has a positive effect on the technical efficiency of Teff farms. The result shows that farmers applied row planting in Teff production due to the pressure of their neighbor farmers. Farmers have a probability of visiting their farm frequently, and then, the efficient farmers might teach their fellow farmers.

\section{Conclusions and policy implications}

There are a lot of studies that have been done on the technical efficiency of farmers in developing countries. But, as far as the authors' knowledge, studies with neighborhood effects on the technical efficiency of Teff farms in Ethiopia are limited. As a result, this study was carried out to estimate the level of technical efficiency and investigate the neighborhood effects on the technical efficiency of Teff farms in Ethiopia using the two waives of ESS data (2014 and 2016).

From the panel stochastic frontier analysis, this study confirmed that there is a chance to increase Teff production and productivity by eliminating the sources of technical inefficiency using the same input levels and existing technology. The maximum likelihood estimates of the stochastic frontier model show that seed, labor, land and mineral fertilizer had a positive and significant effect on Teff production. Thus, the rise in those inputs would increase Teff production. Besides, the correlated random effect estimation of the SLX model indicates that gender, age, education, family size, community participation, planting method, average neighbors' community participation, average neighbors' planting method, average neighbors' mineral fertilizer application, and average neighbors' use of improved seed were found the main sources of technical inefficiencies of Teff farms. Therefore, estimating the neighborhood effects on the technical efficiency of Teff farms are essential and the technical efficiency of Teff farm is influenced by not only farmer own demographic, socioeconomic, and institutional factors, but, also influenced by their neighbors' farm characteristics. Thus, the neighborhood is the best alternative platform for knowledge transmission between peer groups to use inputs wisely and efficiently in their farm operations if it is properly managed and organized. Therefore, the overall implication of neighborhood effects helps to implement suitable and cost-effective knowledgeexchange scheme to improve the level of technical efficiency of Teff producer farmers. 


\section{Abbreviations}

AEZ: Agro-Ecology Zone; CD: Cobb Douglas production function; CIA: Central Intelligence Agency; CRE: Correlated Random Effect; CSA: Central Statistical Agency; DEA: Data Envelopment Analysis; EA: Enumeration Area; ESS: Ethiopian Socioeconomic Survey; ETB: Ethiopian Birr; FAO: Food and Agricultural Organization; GO: Governmental Organization; GTP: Growth and Transformation Plan; ha: hectare; LR: Likelihood Ratio; LSMS-ISA: Living

Standard Measurement Study-Integrated Surveys of Agriculture; m.a.s.l: meter above sea level; MD: Man-Days; MoARD: Ministry of Agriculture and Rural Development; ML: Maximum Likelihood; NGO: Non-Governmental Organization; NPC: National Planning Commission; SLX: Spatial Lagged of X variables; SNNP: Southern Nations' and Nationality People; TE: Technical Efficiency; TLU: Tropical Livestock Unit; VDC: Village Development Committee; VIF: Variance Inflation Factor.

\section{References}

Abebe, G.G., 2014. Off-Farm Income and Technical Efficiency of Smallholder Farmers in Ethiopia: A Stochastic Frontier Analysis. Uppsala, Degree project/SLU, Department of Economics.

Abedullah, A., Sushil, P., Saima, J., 2009. Time varying technical efficiency, evidences from rainfed rice areas of the Philippines. Pakistan Journal of Applied Economics.

Ademe, M., Fikadu, A.A., 2018. Pre-scaling up of improved teff technologies in moisture deficit areas of Wag-Lasta, Eastern Amhara, Ethiopia. Amhara Region Agriculture Research Institute 9th Annual Research conference 177-189.

Adjognon, S., Liverpool-Tasie, L.S., 2015. Spatial Neighborhood Effects in Agricultural Technology Adoption: Evidence from Nigeria. Int. Conf. Agric. Econ. Milan Italy 15.

Ahmed, M.H., Lemma, Z., Endrias, G., 2015. Measuring Technical, Economic and Allocative Efficiency of Maize Production in Subsistence Farming: Evidence from the Central Rift Valley of Ethiopia. Appl. Stud. Agribus. Commer. 9, 63-74. https://doi.org/10.19041/APSTRACT/2015/3/9

AKLDP, T.U.E.A.K., Learning, Documentation and Policy, 2015. Ethiopia's Agriculture Sector Policy and Investment Framework (2010-2020) External Mid-term Review (Policy Evaluation Report). Ethiopia.

Alene, A.D., 2003. Improved production technology and efficiency of smallholder farmers in Ethiopia: Extended parametric and non-parametric approaches to production efficiency analysis. Doctoral dissertation, University of Pretoria, South Africa.

Anselin, L., 2003. Spatial Externalities, Spatial Multipliers, And Spatial Econometrics. Int. Reg. Sci. Rev. 26, 153-166. https://doi.org/10.1177/0160017602250972

Anselin, L., 2001. Spatial Effects in Econometric Practice in Environmental and Resource Economics. American Journal of Agricultural Economics 83, 705-710.

Anselin, L., 1990. SPATIAL DEPENDENCE AND SPATIAL STRUCTURAL INSTABILITY IN APPLIED REGRESSION ANALYSIS*. J. Reg. Sci. 30, 185-207. https://doi.org/10.1111/j.1467-9787.1990.tb00092.x

Anselin, L., 1988. Spatial Econometric methods and models. Kluwer Acad. Publ.

Anselin, L., Bera, A.K., Florax, R., Yoon, M.J., 1996. Simple diagnostic tests for spatial dependence. Reg. Sci. Urban Econ. 26, 77-104. https://doi.org/10.1016/0166-0462(95)02111-6 
Areal, F.J., Balcombe, K., Tiffin, R., 2012. Integrating spatial dependence into Stochastic Frontier Analysis: Integrating spatial dependence into SFA. Aust. J. Agric. Resour. Econ. 56, 521-541. https://doi.org/10.1111/j.1467-8489.2012.00597.x

Assefa, K., Tadele, Z., Chanyalew, S., Ethiopian Institute of Agric. Research, D.Z.C., Universität Bern, Institut für Pflanzenwissenschaften, International Workshop on Achievements and Prospects of Tef Improvement (Eds.), 2013. Achievements and prospects of tef improvement: Proceedings of the Second International Workshop, November 7-9, 2011, Debre Zeit, Ethiopia. Universität Bern, Bern.

Aung, N.M., 2012. Production and Economic Efficiency of Farmers and Millers in Myanmar Rice Industry 85.

Bachewe, F.N., Koru, B., Taffesse, A.S., 2018. Productivity and efficiency of of Teff in High potential areas of Ethiopia, in: The Economics of Teff: Exploring Ethiopia's Biggest Cash Crop. International Food Policy Research Institute, Washington, DC 20005, USA, pp. 149-179.

Battese, G.E., Coelli, T.J., 1992. Frontier production functions, technical efficiency and panel data: With application to paddy farmers in India. J. Product. Anal. 3, 153-169. https://doi.org/10.1007/BF00158774

Battese, G.E., Coelli, T.J., 1988. Prediction of Firm-Level Technical Efficiencies with a Generalized Frontier Production Function and Panel Data. Elsevier Sci. Publ. BV N.-Holl. 38, 387-399.

Battese, G.E., Corra, G.S., 1977. Estimation of a Production Frontier Model: With Application to the Pastoral Zone of Eastern Australia. Aust. J. Agric. Econ. 21, 169-179. https://doi.org/10.1111/j.1467-8489.1977.tb00204.x

Berhane, G., 2014. Emerging Demand for Tractor Mechanization in Ethiopia. Presented at the Mechanization and Agricultural Transformation in Asia and Africa Sharing Development Experiences, IFPRI/Ethiopia Strategy Support Program, Beijing, China, p. 43.

Bockstael, N.E., 1996. Modeling Economics and Ecology: The Importance of a Spatial Perspective. Am. J. Agric. Econ. 78, 1168-1180. https://doi.org/10.2307/1243487

Case, A., 1992. Neighborhood influence and technological change. Reg. Sci. Urban Econ. 22, 491-508. https://doi.org/10.1016/0166-0462(92)90041-X

CIA, 2018. Ethiopian Economy 2018. URL https://theodora.com/wfbcurrent/ethiopia/ethiopia_economy.html (accessed 12.9.18).

CIA, 2017. Africa: Ethiopia - The World Factbook - Central Intelligence Agency [WWW Document]. URL https://www.cia.gov/library/publications/the-world-factbook/geos/et.html (accessed 11.17.18).

CIMMYT, 2014. Market Analysis for small mechanization in Ethiopia (Farm Mechanization and Conservation Agriculture for Sustainable Intensification (FACASI) Project). Ethiopia.

Coelli, T., Rao, D.S., Donnell, C., Battese, G. (Eds.), 2005. An introduction to efficiency and productivity analysis, 2nd ed. ed. Springer, New York.

Crymes, Annete R., 2015. Te International Footprint of Teff: Resurgence of an Ancient Ethiopian Grain (rts \& Sciences Electronic Theses and Dissertations). Washington University in St. Louis.

Crymes, Annette R, 2015. The International Footprint of Teff: Resurgence of an Ancient Ethiopian Grain. Arts \& Sciences Electronic Theses and Dissertations. 394. 99.

CSA, 2018a. Area and Production of Major crops in Ethiopia (Statistical report). Central Statistical Agency, Addis Ababa, Ethiopia. 1, 57.

CSA, 2018b. The 2015/16 Ethiopian Household Consumption-Expenditure (HCE) Survey (Statistical report No. Statistical Bulletin 585-10). Central Statistical Agency, Addis Abeba, Ethiopia.

CSA, 1996-2018. Area and Production of Major crops in Ethiopia (Statistical report). Central Statistical Agency, Addis Ababa, Ethiopia.

Dietz, Robert.D., 2002. The estimation of neighborhood effects in the social sciences: An interdisciplinary approach. Soc. Sci. Res. 31, 539-575. https://doi.org/www.academicpress.com

Dufera, G.L., 2018. The Ethiopian Agricultural Extension System and Its Role as a Development Actor: Cases from Southwestern Ethiopia (PHD Disseration). Bonn Uinversity, Bonn, Germany. 
Evans, L.T., Fischer, R.A., 1999. Yield Potential: Its Definition, Measurement, and Significance. Crop Sci. 39, 1544-1551.

Färe, R., Grosskopf, S., Logan, J., Knox Lovell, C.A., 1985. Measuring Efficiency in Production: With an Application to Electric Utilities, Dogramaci A., Adam N.R. (eds) Managerial Issues in Productivity Analysis. Springer Science+Business Media B.V., Springer, Dordrecht.

Farrell, M.J., 1957. The Measurement of Productive Efficiency. J. R. Stat. Soc. Ser. Gen. 120, 253. https://doi.org/10.2307/2343100

Fikadu, A.A., Tilaye, K.A., Mebrat, A., Elimnh, L.A., 2017. Adoption and Intensity of Use of Modern Beehives in Wag Himra and North Wollo Zones, Amhara Region, Ethiopia. Journal of Ethiopian Economic Association 30.

Gezahegn, A., Mekonnen, B., Samia, Z., 2006. Productivity and Efficiency of Agricultural Extension Package in Ethiopia.

Gibbons, S., Overman, H.G., 2012. Mostly Pointless Spatial Econometrics? Wiley Period. Inc 52, 172191. https://doi.org/10.1111/j.1467-9787.2012.00760.x

Hadri, K., Whittaker, J., 1999. Efficiency, Environmental Contaminants and Farm Size: Testing for Links Using Stochastic Production Frontiers. J. Appl. Econ. 2, 337-356. https://doi.org/10.1080/15140326.1999.12040542

Halleck Vega, S., Elhorst, J.P., 2015. The SLX model. Wiley Period. Inc 55, 339-363. https://doi.org/10.1111/jors.12188

Holloway, G., Shankar, B., Rahmanb, S., 2002. Bayesian spatial probit estimation: a primer and an application to HYV rice adoption. Agric. Econ. 27, 383-402. https://doi.org/10.1111/j.15740862.2002.tb00127.x

Jemal, M.K., Schmidt, E., Tilahun, H., 2018. Market Access, Teff Production, and Fertilizer Use Over Time, in: The Economics of Teff: Exploring Ethiopia's Biggest Cash Crop. International Food Policy Research Institute, Washington, DC.

Krishnan, P., Patnam, M., 2012. Neighbours and Extension Agents in Ethiopia: Who matters more for technology diffusion? 37.

Lapple, D., Kelley, H., 2015. Spatial dependence in the adoption of organic dry stock farming in Ireland. Eur. Rev. Agric. Econ. 42, 315-337. https://doi.org/10.1093/erae/jbu024

Lavrakas, P.J., 2008. Interaction Effects. Encycl. Surv. Res. Methods.

Lobell, D.B., Cassman, K.G., Field, C.B., 2009. Crop Yield Gaps: Their Importance, Magnitudes, and Causes. Annu. Rev. Environ. Resour. 34, 179-204. https://doi.org/10.1146/annurev.environ.041008.093740

Maertens, A., 2009. Who Cares What Others Think (or Do)? Social Learning and Social Pressures in Cotton Farming in India. Am. J. Agric. Econ. 99, 988-1007. https://doi.org/10.1093/ajae/aaw098

Manski, C.F., 1993. Identification Problems in the Social Sciences. Am. Sociol. Assoc. 23, 1-56.

MoARD, 2010. ETHIOPIA'S AGRICULTURAL SECTOR POLICY AND INVESTMENT FRAMEWORK (PIF).

Mundlak, Y., 1978. On the Pooling of Time Series and Cross-Section Data. Econometrica 46, 69. https://doi.org/10.2307/1913646

Nivievskyi, O., 2009. Price Support, Efficiency and Technology Change of Ukrainian dairy farms: Spatial dependence in the components of productivity growth 16 .

NPC, 2016. Gowth and Transformation Plan II (2015/16-2019/20)). National Planning Commission, Addis Ababa, Ethiopia.

Pede, Valerien O., McKinley, J., Singbo, A., Kajisa, K., 2015. Spatial Dependency of Technical Efficiency in Rice Farming: The Case of Bohol, Philippines.

Pede, Valerien O, McKinley, J., Singbo, A., Kajisa, K., 2015. Spatial Dependency of Technical fficiency in Rice Farming: The Case of Bohol, Philippines, in: Agricultural \& Applied Economics Association and Western Agricultural Economics Association Annual Meeting, San Francisco, CA, July 26-28. p. 39.

Quintin, G., Tefera, A., 2013. Ethiopia Grain and Feed Annual Report (No. ET-1301). 
Rapsomanikis, G., 2015. The economic lives of smallholder farmers. Food Agric. Organ. U. N. FAO Rome 48. https://doi.org/www.fao.org/publications

Saint-Cyr, L.D.F., Storm, H., Heckelei, T., Piet, L., 2019. Heterogeneous impacts of neighbouring farm size on the decision to exit: evidence from Brittany. Eur. Rev. Agric. Econ. 46, 237-266. https://doi.org/10.1093/erae/jby029

Schmidtner, E., Lippert, C., Engler, B., Häring, A.M., Aurbacher, J., Dabbert, S., 2012. Spatial distribution of organic farming in Germany: does neighbourhood matter? Eur. Rev. Agric. Econ. 39, 661-683. https://doi.org/10.1093/erae/jbr047

Solís, D., Bravo-Ureta, B.E., Quiroga, R.E., 2007. Soil conservation and technical efficiency among hillside farmers in Central America: a switching regression model. Aust. J. Agric. Resour. Econ. 51, 491-510. https://doi.org/10.1111/j.1467-8489.2007.00394.x

Spielman, D.J., Byerlee, D., Alemu, D., Kelemework, D., 2010. Policies to promote cereal intensification in Ethiopia: The search for appropriate public and private roles. Food Policy 35, 185-194. https://doi.org/10.1016/j.foodpol.2009.12.002

Storm, H., Heckelei, T., 2015. Local and regional spatial interactions in the analysis of Norwegian farm growth. 150th EAAE Semin. Edinb. UK 21.

Taffesse, A.S., Dorosh, P., Gemessa, S.A., 2012. Crop Production in Ethiopia: Regional Patterns and Trends, in: Food and Agriculture in Ethiopia: Progress and Policy Challenges. University of Pennsylvania Press, Philadelphia, pp. 89-129.

Tessema, Y.M., Asafu-Adjaye, J., Kassie, M., Mallawaarachchi, T., 2016. Do neighbours matter in technology adoption? The case of conservation tillage in northwest Ethiopia. African Journal of Agricultural and Resource Economics 11, 15.

Tiruneh, W.G., 2013. TECHNICAL EFFICIENCY OF SMALLHOLDER WHEAT AND BARLEY FARMERS: THE CASE OF WELMERA DISTRICT, OROMIA REGIONAL STATE, ETHIOPIA M. A THESIS 130.

Vandercasteelen, J., Dereje, M., Minten, B., Taffesse, A.S., 2014. Perceptions, Impacts and Rewards of Row Planting of Teff. SSRN Electron. J. https://doi.org/10.2139/ssrn.2530422

Vandercasteelen, J., Dereje, M., Minten, B., Taffesse, A.S., 2013. The impact of scaling up row planting on farmers' teff yield (Conference paper), Improved evidence towards better policies for the teff value chain. International Food Policy Research Institute ESSP-II, Addis Ababa, Ethiopia. https://doi.org/10.2499/9780896296756

Villanueva, D.B., Pede, V.O., Rodriguez, U.-P.E., Sumalde, Z.M., Garcia, Y.T., 2017. Assessment of Neighborhood and Spillover Effects on Technical Efficiency of Irrigated Rice Farmers. Asian Journal of Agriculture and Development 14, 23.

Wassie, S.B., 2014. Technical Efficiency of Major crops In Ethiopia: Stochastic Frontier Model 57.

Woldeyohanes, T., Heckelei, T., Surry, Y., 2017. Effect of off-farm income on smallholder commercialization: panel evidence from rural households in Ethiopia. Agric. Econ. 48, 207-218. https://doi.org/10.1111/agec.12327

Wollie, G., 2018. Technical Efficiency of Barley Production: The Case of Smallholde Farmers in Meket District, Amhara National Regional State, Ethiopia. https://doi.org/10.20944/preprints201801.0253.v1

Wollni, M., Andersson, C., 2014. Spatial patterns of organic agriculture adoption: Evidence from Honduras. Ecol. Econ. 97, 120-128. https://doi.org/10.1016/j.ecolecon.2013.11.010

Wooldridge, J.M., 2010. Econometric Analysis of Cross Section and Panel Data, 2nd ed. MIT Press, Cambridge, Massachusetts, London, England.

World Bank, 2017. Agriculture, Forestry, and Fishing, Value added (percent of GDP) of Ethiopia. 


\section{Figures}

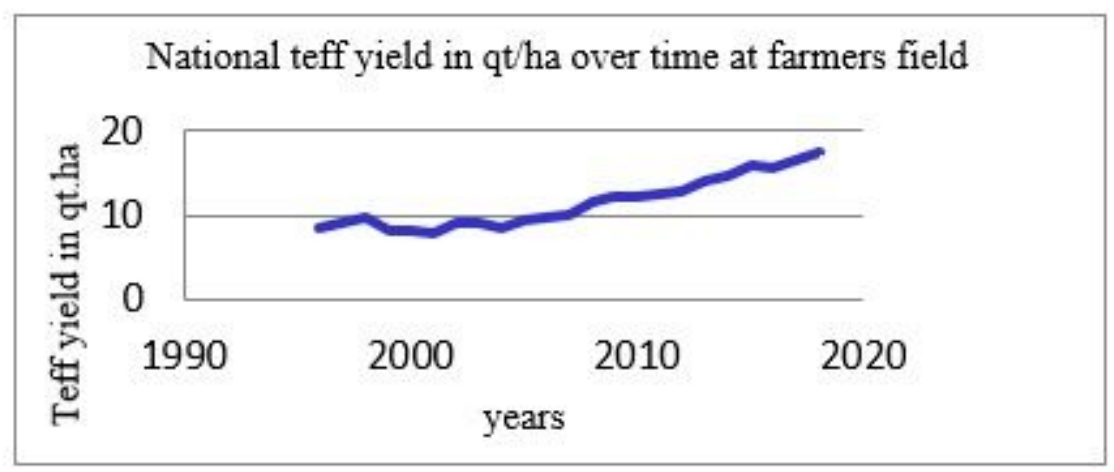

Figure 1

Teff yield trend between 1996 and 2018 Source: Own analysis based on CSA (1996 - 2018)

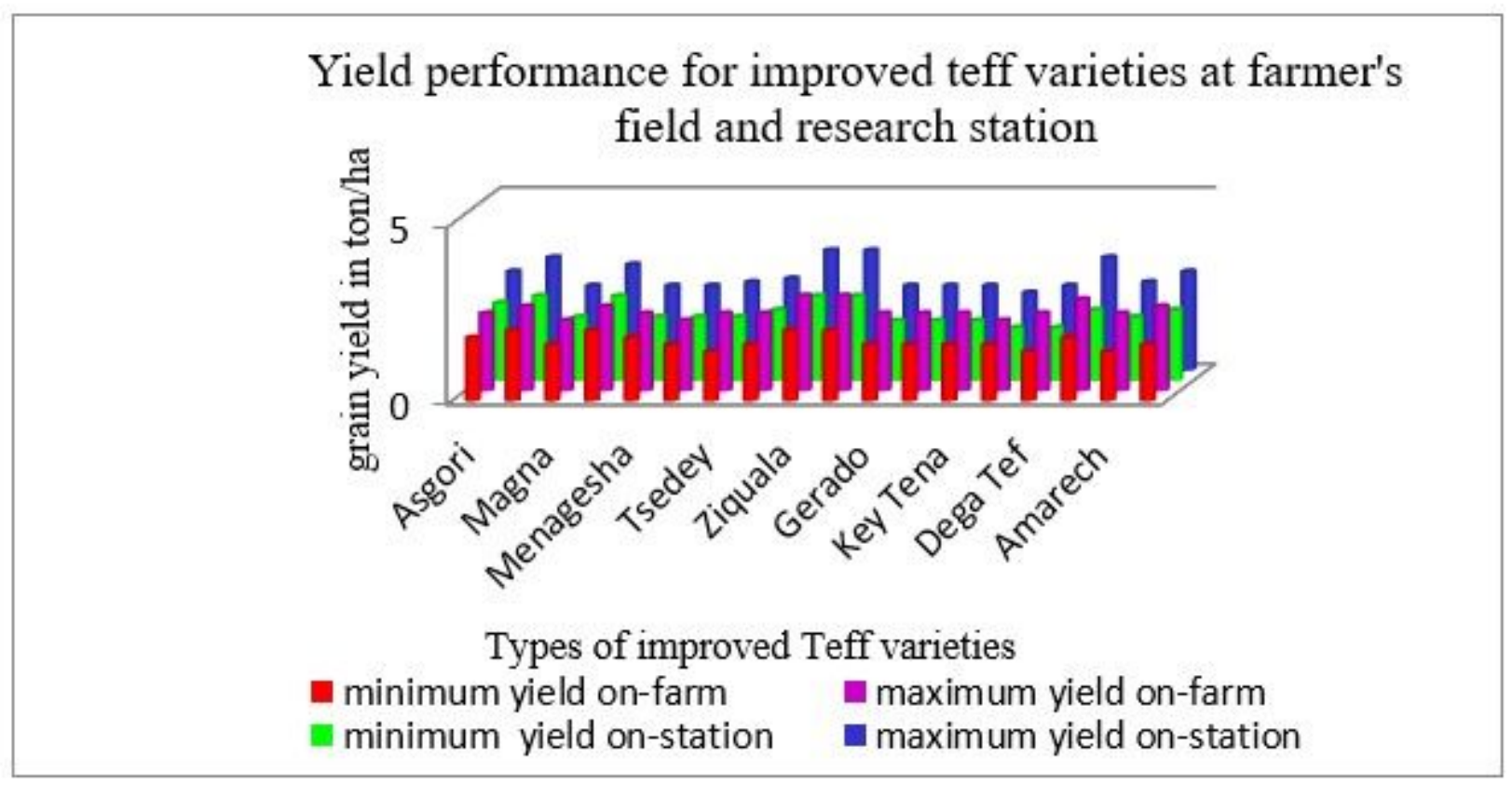

Figure 2

Yield variation for different improved Teff varieties on-station and on-farm level Source: Own analysis based on MoARD (2010) and Assefa et al. (2013). 


\section{Distribution of Technical Efficiency scores}

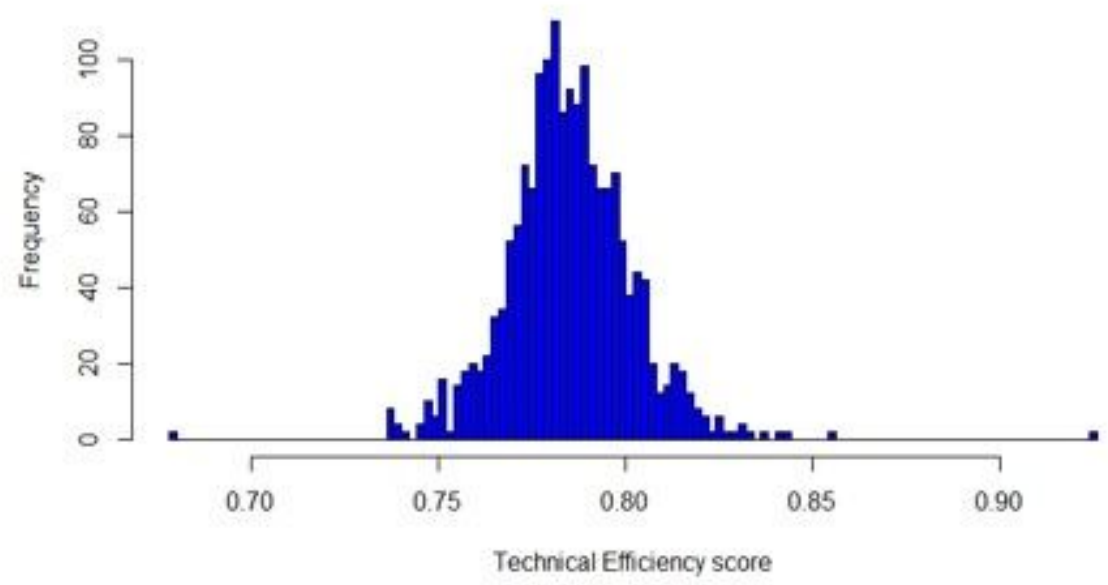

\section{Figure 3}

Distribution of Technical Efficiency of Teff farms Source: Own analysis based on the pooled ESS (2013/14 and 2015/16) data

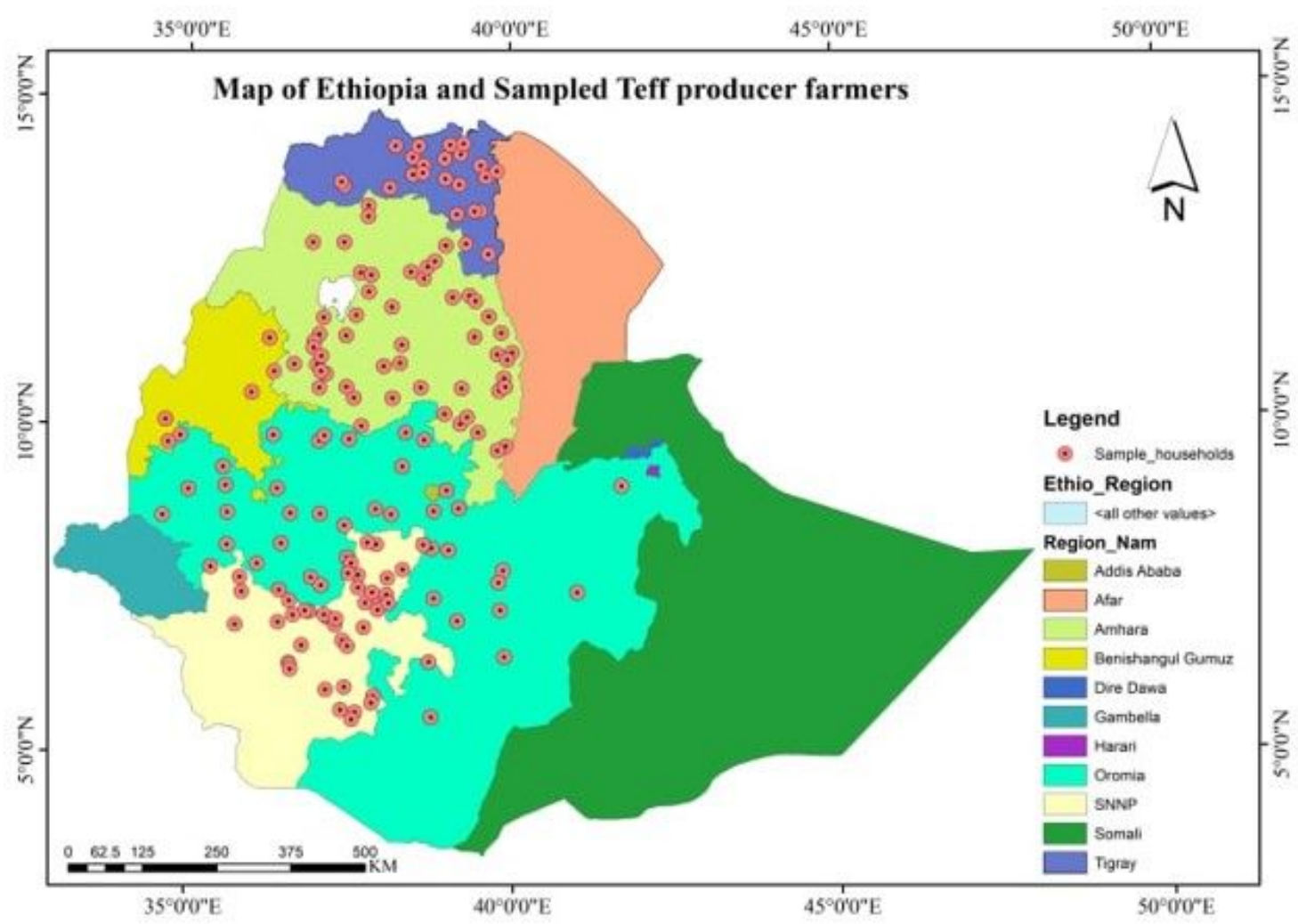

\section{Figure 4}

The distribution of the sampled Teff producing farmers across regions. Source: Own analysis based on ESS (2014 and 2016) data 


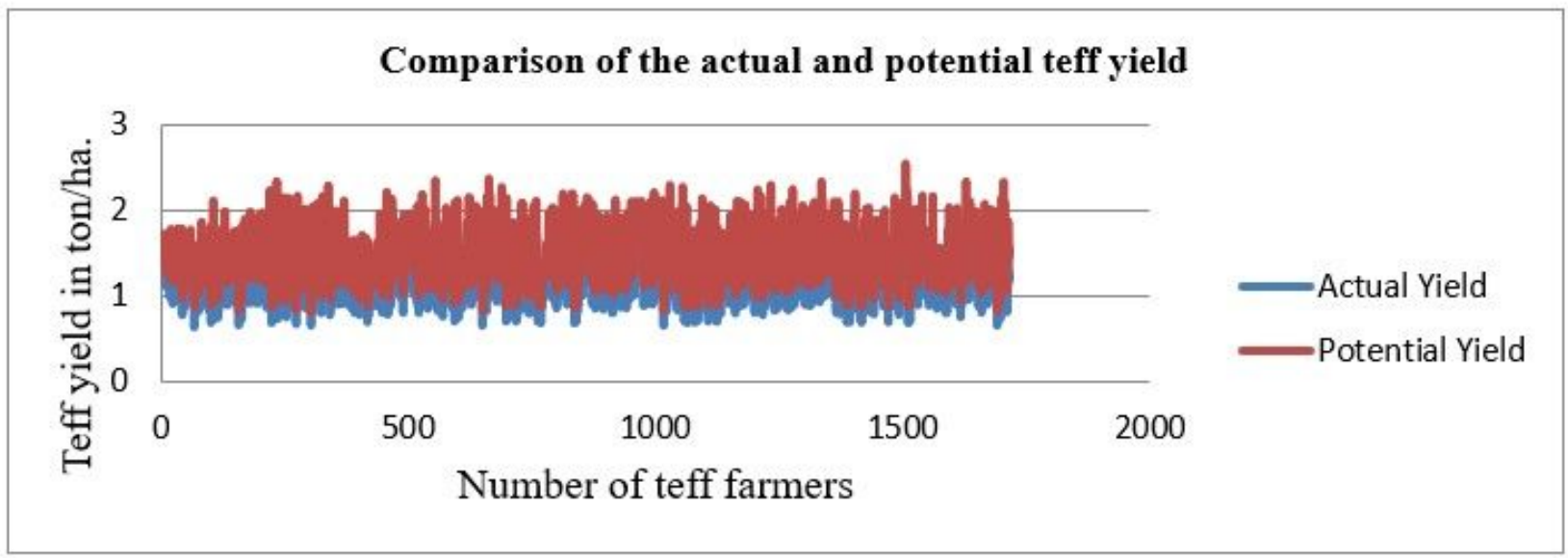

\section{Figure 5}

Graphical analysis of Teff yield gap due to technical inefficiency Source: Own analysis based on ESS (2014 and 2016) data

\section{Supplementary Files}

This is a list of supplementary files associated with this preprint. Click to download.

- renamedeb91b.docx 